\title{
François Tosquelles, sua história no campo da Reforma Psiquiátrica / Desinstitucionalização e suas pistas para uma abordagem clínica do trabalho centrada na atividade
}

\section{François Tosquelles, their history in the Psychiatric Reform - Deinstitutionalization and their clues to a clinical approach focused on the work activity}

\author{
Valéria Salek Ruiz* \\ Psicóloga da Petrobras, Rio de Janeiro, Rio de Janeiro, Brasil \\ Vladimir Athayde** \\ Psicólogo do Hospital da Mulher Mariska Ribeiro, Rio de Janeiro, Brasil
}

\section{I rapoan Nogueira Filho***}

Universidade Federal Rural do Rio de Janeiro - UFRRJ, Campus Três Rios, Rio de Janeiro, Brasil

\section{Paulo César Zambroni-de-Souza**** \\ Universidade Federal da Paraíba - UFPB, J oão Pessoa, Paraíba, Brasil}

\section{Milton Athayde*****}

Universidade do Estado do Rio de Janeiro - UERJ, Rio de Janeiro, Brasil

\begin{abstract}
RESUMO
O artigo revisita aspectos da vida e da obra do psiquiatra catalão François Tosquelles, registrando a trajetória e o patrimônio de experimentações no campo da saúde mental, em especial em sua valorização da atividade. Para tanto, foi feito um levantamento bibliográfico dos textos por ele publicados, assim como das entrevistas que concedeu, além de materiais publicados por outros autores que se referem a ele ou à sua obra. Entende-se que aí se encontra uma riqueza ainda pouco explorada e que tal pesquisa permite avançar: seja na luta pela reforma psiquiátrica e desinstitucionalização; seja, enfim, explorando o ponto de vista da atividade na abordagem clínica do trabalho.
\end{abstract}

Palavras-chave: Tosquelles, Reforma Psiquiátrica, Desinstitucionalização, Saúde Mental, Atividade.

\section{ABSTRACT}

This paper raises some aspects of the life and work of the Catalan psychiatrist Francois Tosquelles, recording the history and heritage of his experiments in the mental health area, especially, in making the activity invaluable. It was pursued to a conduct a bibliographical survey on the texts 
Valéria Salek Ruiz, Vladimir Athayde, I rapoan Nogueira Filho, Paulo César Zambroni-de-Souza, Milton Athayde

François Tosquelles, sua história no campo da Reforma Psiquiátrica / Desinstitucionalização e suas pistas para uma abordagem clínica do trabalho centrada na atividade

published by him was sought after as well as on the interviews he gave, in addition to materials published by several other authors who refer to him or his work. We take it that there is still an unexplored richness in various Psychology fields, whether in the struggle for deinstitutionalization and psychiatric reform with new forms of psychosocial care whether in the pursuit of possibilities for intervention research and, finally, exploring the activity viewpoint in relation to the clinic approach of work.

Keywords: Tosquelles, Psychiatric Reform, Desinstitutionalization, Mental Health, Activity.

\section{I ntrodução}

O fio condutor do artigo é o patrimônio que o psiquiatra catalão François Tosquelles (1912-1994) nos legou. Tendo já pistas sinalizadas na literatura acerca de suas contribuições (DELION, [1967]/2009; GALLIO e CONSTANTINO, 1994; BILLIARD, 2001; CLOT, 2009), buscou-se fazer um levantamento bibliográfico mais completo dos textos por ele publicados, subsidiando o desenvolvimento da análise das questões e pistas indicadas pelo autor. A pesquisa levou a delimitar o foco nos materiais de sua experimentação inicial, no período que vai da guerra civil espanhola ao imediato pós-guerra, tendo já como terreno de atuação a França, para onde teve que fugir com a vitória armada do fascismo franquista. Decidiu-se por indicar, ao final do texto, o levantamento a que se chegou de sua obra. Apesar de não estarem todos citados no artigo, apresenta-se o inventário como contribuição para os interessados da comunidade científica pertinente.

Foram também incorporadas para a análise algumas conversas/entrevistas do autor, dado entender-se que essa modalidade de explicitação do pensamento tem revelado grande fecundidade para compreender a experiência e a obra de muitos pensadores e práticos. Nesse gênero se destaca uma longa conversa ao longo de três dias, em 1987, com profissionais de saúde mental da França e da Itália (ligados à Basaglia e à Psiquiatria Democrática), parcialmente registrada e mais parcialmente publicada em um dos números da coleção Saúdeloucura, da editora Hucitec (GALLIO e CONSTANTINO, 1994).

Em movimento investigativo complementar, buscou-se verificar como foi incorporada sua contribuição em três diferentes campos e daí o que elas nos informam. Quanto ao levantamento histórico da Reforma Psiquiátrica e Desinstitucionalização no Brasil, assim como o impacto da trajetória de Tosquelles neste campo, contou-se com os estudos publicados por Amarante (2007, 2003a, 2003b, 1994), Verstsman, Cavalcanti e Serpa Junior (1992), Birman e Costa (1994), Passos (2009), entre outros. Quanto à contribuição de Tosquelles para o movimento institucionalista (em especial as abordagens da 
Análise Institucional e da Esquizoanálise), destacam-se os materiais que se encontram na produção de Rodrigues (1993, 1998), Barros (2007) e Moura (2003), como em textos de Hess (1983) e Guattari (1985), no caso da França. Chegamos a iniciar sua interface com a Psicanálise, mas o material levantado e o esboço analítico não foram suficientes para chegar à consistência mínima necessária para uma publicação, ficando para outro momento.

Enfim, quanto às suas contribuições para o campo do trabalho e da Clínica do Trabalho, foram selecionados textos de autores que de algum modo consideram o patrimônio de Tosquelles. Cronologicamente os primeiros a fazê-lo foram os fundadores oficiais da Psicopatologia do Trabalho (PPT) na França (como Louis Le Guillant e outros), seguidos por Dejours (1993), da geração seguinte. Já neste início de século outros autores franceses vêm explorando mais rigorosamente Tosquelles, como Billiard (2001), ao investigar a emergência da PPT na França. Assim como Clot (2006a), primeiro ao compará-lo com Le Guillant, em seguida ao explorar as possibilidades contidas na obra de Tosquelles para melhor compreender as relações entre trabalho e atividade, assim como as operações de análise do trabalho (2009; 2010).

Foi com estes materiais que se trabalhou sobre o patrimônio gerado por Tosquelles, de modo a se produzir pistas que colaborem para o desenvolvimento deste campo mais amplo da vida, que envolve saúde, atividade e trabalho.

\section{Experimentações iniciais na Catalunha / Espanha e a fuga para a França}

Tosquelles nasceu em 1912, na cidade de Réus, ao sul de Barcelona, na região da Catalunha. Ali se formou em Medicina (1927-1935), especializando-se em Psiquiatria e trabalhando no Instituto Pere Mata, onde grandes psiquiatras atuaram, como Emilio Mira y Lópes. Tudo indica que Tosquelles foi muito influenciado pessoal e profissionalmente por este meio sociocultural.

Lutou na Guerra Civil Espanhola, mergulhando no combate com as milícias antifascistas. O Instituto Psiquiátrico de Pere Mata, com a Guerra Civil, foi obrigado a evacuar os internados e tornou-se um Banco de Sangue para atender os feridos republicanos da região. Mira y Lópes ascendeu a chefe do Serviço de Higiene Mental do Exército da República, sendo Tosquelles enviado para a frente sul como médico-chefe dos serviços psiquiátricos do Exército, criando então uma Comunidade Terapêutica em Almodóvar del Campo. Ali organizou um Serviço, recrutando pessoas para atuar como agentes de saúde, evitando incluir psiquiatras profissionais, no entendimento de que teriam deformação profissional e até mesmo fobia da loucura. 
Aliás, o Serviço teve entre seus usuários os próprios médicos, porque na opinião de Tosquelles seus colegas tinham forte medo da guerra civil, pois foram ideologicamente formados para a estabilidade da vida burguesa. Assim, promoveu o uso de psicoterapia com essas pessoas para evitar a emergência de crises, já existindo ali a prática de tratar não apenas os internos, mas todos os presentes no Serviço. Em uma conversa com profissionais de saúde mental da Itália e França, publicada no Brasil (GALLIO \& CONSTANTINO, 1994), Tosquelles fala que optou pelo recrutamento de leigos, sem experiência de trabalho com pessoas com graves transtornos mentais, pois ao menos seriam menores os preconceitos e teriam uma postura positivamente ingênua com eles. Aposta até mesmo na grande experiência e sensibilidade das prostitutas para a convivência com homens, aproveitando-se de que, com a Guerra, elas tinham sua vida profissional dificultada e até mesmo proibida, formalmente. Teria tido sucesso na empreitada, dado que muitos usuários do Serviço revelaram significativas melhoras. Com a vitória militar do franquismo, em março de 1939 Tosquelles foge para a França, levando um patrimônio de diversas experiências insólitas. Esconde-se em uma casa de reclusão de nome Hospice de France, tenta sem sucesso entrar para o exército francês, em seguida infiltra-se em um campo de concentração (em Sept-fonds), onde fica por um ano e meio. Por um lado haviam muitos suicídios, e ao mesmo tempo a ausência de um serviço psiquiátrico que desse conta da gravidade dos transtornos mentais então emergentes. Tendo o comandante sensibilidade para a situação, Tosquelles acaba atuando informalmente como psiquiatra, em situação dramática, sem qualquer condição objetiva. Ele se valeu dessa situação não só para tratar dos pacientes, como também para facilitar suas fugas.

Em janeiro de 1940 ele consegue um convite de trabalho, com a ajuda de colegas psiquiatras atuando na França. O também catalão Salvador Vives, que com a derrota para os fascistas na guerra civil espanhola havia, como ele, fugido para a França, fala sobre Tosquelles a André Chaurand, que o indica a Paul Balvet (um psiquiatra francês católico que lutava na Resistência). Vives sugere a Balvet, com sucesso, que convidasse Tosquelles para trabalhar no Hospital Psiquiátrico de Saint Alban (na região montanhosa de Lozère), então sob sua direção. Ele tem assim a possibilidade de ali atuar, iniciando em 1941 um intenso campo de experimentações de novas formas de organização do hospital e do trabalho terapêutico.

\section{A experiência deflagradora no Hospital Psiquiátrico de Saint- Alban / França: um lugar de acolhida e passagem}


Em plena Segunda Guerra Mundial, em um país como a França, cujo governo optou pela colaboração com Hitler, sendo em seguida ocupado pelas forças armadas nazistas, ocorreu uma das experiências mais relevantes e férteis em termos de questionamento e renovação das práticas no campo da Psiquiatria. A perspectiva que se abria era a seguinte: cuidar do hospital para que ele pudesse tornar-se efetivamente agente de saúde mental, dado que ele segregava sua própria patologia, com base no confinamento de todos, inclusive os profissionais de saúde, cronificando-os. Nas palavras de Tosquelles, "trata-se de fazer trabalhar os doentes e o pessoal cuidador para cuidar da instituição" ([1967] 2009, p. 79, grifo do autor, apud BILLIARD, 2001), concepção que ele diz já presente nas proposições do psiquiatra alemão Hermann Simon, sistematizada nos anos 1920. Tal concepção e prática que vão caracterizar Tosquelles vai ser, posteriormente, designada pela expressão "Psicoterapia Institucional", a partir de um artigo publicado pelos psiquiatras franceses Daumézon e seu discípulo Koechlin (DAUMÉZON e KOECHLIN, 1952).

Sua formação pessoal e profissional na região espanhola da Catalunha teve a parceria com revolucionários e artistas, em especial os surrealistas, tudo indica que com efeitos para sua ousadia, criatividade, semeando as inovações instituídas nas experimentações de Saint-Alban. Já na França, neste contexto ocorreram significativos encontros, no próprio Manicômio, com destacadas figuras da intelectualidade, muitos militantes da Resistência, na luta clandestina pela Liberação, como Georges Canguilhem. Também importantes encontros no próprio campo da Psiquiatria, inclusive com os fundadores da Psicopatologia do Trabalho, como Louis Le Guillant e Paul Sivadon.

Embora a localização do hospital fosse distante dos grandes centros urbanos $^{1}$, Saint-Alban - há muito governado por freiras da congregação de Saint Régis, recebendo 500 internos - rompia em diversos aspectos, na prática, com a tradição de isolamento dos manicômios. Chegando ao hospital, antes mesmo de querer implantar mudanças, Tosquelles procurou compreender a estranheza que percebia em seu funcionamento. Ele relata que antes de sua chegada, dado o quadro de abandono pelas condições da 2 a Guerra (na França, $40 \%$ dos classificados como doentes mentais morreram de fome), o hospital - medieval, sujo e superpovoado - tinha se tornado um local aberto, de passagem, pois representava o caminho natural por onde os camponeses e suas vacas e mercadorias atravessavam para chegar à feira da região. Este movimento territorial acabava propiciando atividades de comércio e trocas com os internados. Aliás, para Tosquelles, esta era uma importante característica na definição de um Serviço de Psiquiatria: ser um lugar 
de passagem, um aportamento ${ }^{2}$, e não exclusivamente para os usuários de um hospital psiquiátrico.

No período de ocupação e guerra nazi-fascista, Saint-Alban se afirmou como um local de passagem e de acolhida, tendo recebido refugiados oriundos de diferentes campos, seja de intelectuais a artistas, judeus, militantes da Resistência. É neste sentido que Tosquelles diz preferir a denominação Asilo. Muitos dos acolhidos e voluntários que por lá passaram, vivendo períodos diversos, puderam contribuir e colocar sua inteligência a serviço das práticas em curso. Especialmente a partir de 1942, quando o psiquiatra Lucien Bonnafé tornou-se diretor e com sua sensibilidade viabilizou estas circulações. Como foi assinalado, um destes grandes intelectuais foi o filósofo e médico Canguilhem:

George Canguilhem e sua família chegaram a Saint-Alban naquele ano. Foi lá que escreveu os capítulos finais de seu livro O normal e o patológico. Então chegaram Paul Éluard e Nouche, sua esposa: uma mulher de teatro que trabalhou bastante conosco, demonstrando extraordinárias habilidades com pacientes esquizofrênicos. (TOSQUELLES, in GALLIO e CONSTANTINO, 1994, p.105)

Com relação a Bonnafé, sua ligação com o Partido Comunista Francês stalinista não o impedia de ter vários pontos em comum com Tosquelles. Desde 1930 ele fora membro de um grupo surrealista de Toulouse. Também participava da luta antifascista e por isso em 1934 foi condenado a dois anos de prisão. Junto com o psiquiatra Georges Daumezon (Hospital Fleury-les-Aubrais) e Germaine Le Guillant teve um papel relevante nas mudanças na formação do pessoal psiquiátrico, em especial de enfermagem. Este empreendimento foi encaminhado via CEMEA (Centros de Treinamento nos Métodos de Educação Ativa).

\section{O campo da Reforma Psiquiátrica e desinstitucionalização}

Na literatura sobre Tosquelles costuma-se lembrar a situação de sua fuga da Espanha e os dois livros que o acompanharam nesta aventura até Saint Alban: um do psiquiatra alemão Hermann Simon, fundador da Ergoterapia e outro de Lacan, fundador de uma abordagem da Psicanálise à qual cada vez mais se ligou.

Em uma época em que se praticava a clinoterapia (repouso no leito), deixando-se os internos inativos, o psiquiatra alemão Simon (18671947) em 1927 sistematiza uma proposição denominada 'psicoterapia (hiper)ativa', depois conhecida por "Ergoterapia", a partir das práticas que desenvolvia desde 1905 no hospital de Warstein e depois em Gutersloh. Em 1929 este psiquiatra publicou o livro "Uma 
terapêutica mais ativa no hospital psiquiátrico". Em conformidade com Bleuler, entendia a vida como atividade incessante, a ser devidamente orientada, opondo-se ao desenvolvimento do patológico, colaborando para a retomada da vontade e do poder de autoconduzir-se de um modo ordenado e útil.

Mas, como diz Saraceno (2001), a utilização do trabalho em Psiquiatria é tão antiga quanto o manicômio, ela é constitutiva da própria Psiquiatria como especialidade médica, ligada à organização do capitalismo industrial (séculos XVII-XVIII), quando se consolida a representação do trabalho como eixo societário regulador e do ócio como uma afronta a Deus. Contudo, é importante esclarecer que tipo de concepção de trabalho predomina, naquele momento, na Psiquiatria: não se trata do trabalho como experiência constitutiva do humano e de seu psiquismo, nem mesmo como forma-mercadoria ou como força de trabalho para o capital (trabalho abstrato). Tem sido predominante o exercício de um trabalho inútil, sem sentido, até hoje produzindo peças sem efetivo valor de utilidade ou estético, seja em hospícios ou em CAPS:

\footnotetext{
"o trabalho humano, após ser cuidadosamente desumanizado e tornado anônimo, despersonalizado e despersonalizante, tornou-se uma atividade desafetada e desabusada, inclusive nos Asilos (...)" (TOSQUELLES, [1967] /2009, p. 20).
}

A tradição ergoterápica que Tosquelles mobiliza é diferente daquela encaminhada por Pinel e Esquirol,. No chamado Tratamento Moral, o trabalho era entendido como possível e desejável, mas era viabilizado (de acordo com a Lei de 1848, na França: "O trabalho aplicado aos alienados") pelo isolamento em relação à sociedade, buscando-se estabelecer uma dada ordem no cotidiano via regime disciplinar do Asilo, no exercício de uma rotina de horários e atividades de trabalho, visto como uma forte terapêutica contra o delírio (DESVIAT, 1999). Em nossa compreensão, com o Tratamento Moral não se busca recuperar a força de trabalho até então improdutiva para a reprodução ampliada de capital. Entendemos que ao invés de seu pretenso efeito terapêutico, essa modalidade de exercício do trabalho busca sim melhorar a participação do internado na vida societária asilar. Como diz a Lei, o trabalho se destina a "tornar o alienado dócil, tranqüilo, ordenado em todos os seus atos" (apud BILLIARD, 2001, p. 107). Ou seja, com este dispositivo busca-se, isto sim, reduzir os conflitos e colaborar para a governabilidade (da sociedade e do hospital). Não se trata de incorporar o asilado no circuito da produção de valor de capital. Seus efeitos giram sim em torno da busca de redução de custos no gerenciamento dos gastos públicos. E neste caso rigidamente, exigindo-se inclusive uma jornada de 10h/dia! 
Esta questão vai se modificando ao longo da história, até configurarse como recurso de "reabilitação psicossocial", nos moldes do que se encontra nas reformas psiquiátricas italiana (ROTELLI, 2000) e brasileira, passando pelo controle social, tratamento moral, ergoterapia, laborterapia, praxiterapia, terapia ocupacional. Ou seja, a Ergoterapia de Simon (1937) é uma das proposições neste questionamento, sendo pertinente verificar as diferenças. No artigo chama-se atenção de que parece um equívoco simplificar a história, restringindo Simon ou Tosquelles como precursores, esgotados ou superados.

Entende-se que o momento atual pode vir a ser rico para o debate sobre a função psicológica do trabalho (Clot, 2006). Neste caso a partir da situação limite (dos transtornos mentais graves), fazendo emergir as possíveis reservas de alternativas (SCHWARTZ, 2000) aí presentes em potêncial. O que parte da comunidade científica do campo da Saúde Mental e mais especificamente Saúde Mental e Trabalho vem publicando (COSTA e FIGUEIREDO, 2004; RUFFEIL, 2009; NOGUEIRA Fo., 2008; ZAMBRONI-DE-SOUZA, 2006) colabora de forma significativa para melhor colocar a questão e o debate acerca das pistas abertas por Tosquelles, especialmente no que se refere à ênfase nas atividades (de trabalho).

$\mathrm{Na}$ experimentação de Saint Alban diversos psiquiatras travaram uma polêmica em torno da questão da atividade, especialmente a de trabalho. Saint Alban colaborou para a emergência de um conjunto de posições em Psicopatologia do Trabalho, na França (DEJ OURS, 1980; DOPLER e DEJ OURS, 1985; ATHAYDE, 1996; BILLIARD, 2001), como será apresentado mais adiante. Uma delas é a corrente de Paul Sivadon (um dos fundadores da PPT, responsável pelo hospital de Ville Evrard, em Neuilly-sur-Marne), para quem a terapêutica ocupacional não visava entreter, distrair o doente, ou com ele reduzir os gastos hospitalares. Visava, sim, à reestruturação da personalidade enferma, utilizando-se das capacidades e níveis funcionais que cada um preservava no momento. Houve divergência entre ambos quanto à valorização da heterogeneidade dos usuários, pois para Tosquelles, caso houvesse no Serviço um processo seletivo de usuários de mesma procedência, nenhum seria curado. Em seu entendimento, em oposição a Sivadon, a cura só é possível ao estar em contato com alguém diferente, em termos de caráter e de estrutura.

Uma das expressões da valorização da heterogeneidade podia ser constatada na eclética composição das equipes. Em sua montagem participavam também pessoas que ainda não tinham passado por uma "deformação profissional" (GALLIO e CONSTANTINO, 1994, p. 99), não se limitava aos tradicionais especialistas, gente que, para ele, na maior parte das vezes, atrapalhava o processo de construção de bons serviços psiquiátricos. Neste contexto de guerra e 
precariedade, eram atraídos voluntários e uma característica valorizada era a competência de estar e saber viver com os outros. Outra figura expressiva da Psicoterapia Institucional ( $\mathrm{PI}$ ), o psiquiatra e em seguida psicanalista lacaniano Jean Oury (2009) - que lá fez seu internato a partir de 1947 - recupera e reconhece a relevância deste ponto insistentemente destacado por Tosquelles:

Essa heterogeneidade é tão importante que parece que o que
é eficaz nem é tanto a abordagem direta, frontal de cada
pessoa, em cada lugar, mas bem a possibilidade de passar
de um lugar a outro e de uma pessoa a outra. (OURY, [1984]
2009, p. 26)

Outro dispositivo criado por Tosquelles foi o Clube Terapêutico, posteriormente explorado muito fertilmente por Oury (acompanhado por Guattari), na Clínica La Borde. Trata-se de algo complexo, a base mesma da Psicoterapia Institucional, um amplo conjunto de atividades por livre adesão, autoexcluídos os médicos, no caso de La Borde. Em 1947 criou-se o que se tornará um protótipo, o Clube Paul Balvet, aproveitando-se da legislação de 1901, que viabilizava atividades associativas no manicômio, posteriormente (1958) tornado lei. O objetivo imediato era o de poder organizar a vida cotidiana de um Serviço, assumindo a responsabilidade das compras e despesas de cada ateliế.

A partir de 1950 criam o jornal "Traço de união" (semanal, depois bimensal), inteiramente produzido no próprio estabelecimento, publicação em que qualquer um poderia escrever sobre o que quisesse.

$\mathrm{Na}$ comunidade psiquiátrica, já em 1942, Tosquelles e Balvet apresentaram em um Congresso em Montpellier (França) a posição de que tanto o hospital psiquiátrico quanto a sociedade em que o asilo se insere estavam doentes e o que é pior: tornaram-se adoecedores. Naquele evento denunciam o imobilismo e decadência do sistema asilar francês, considerando estarem os internos submetidos a um verdadeiro genocídio. No caso de Saint Alban todo o coletivo envolvido era quem garantia a sobrevivência.

Quanto ao estatuto profissional de Tosquelles, o governo francês nunca reconheceu seu diploma espanhol de psiquiatra. Em 1946 sua situação foi regularizada, mas em um posto de enfermeiro, enquanto ele refazia sua formação médica no país. Ele seguiu toda a carreira da hierarquia, só se tornando diretor de Saint Alban em 1953, doze anos após sua chegada.

Em 1951 Henri Ey organizou as "Jornadas de Bonneval", evento em que Tosquelles apresenta a organização a que chegaram em SaintAlban, desenvolvendo as bases de uma "psicoterapia coletiva", que 
François Tosquelles, sua história no campo da Reforma Psiquiátrica / Desinstitucionalização e suas pistas para uma abordagem clínica do trabalho centrada na atividade

no ano seguinte Daumézon e Koechlin (1952) vão denominar "Psicoterapia Institucional", como dissemos.

Neste processo criou-se o que Tosquelles denominava carinhosamente "a banda" (GALENDE, 1990, p. 150), a Sociedade de Gévaudan, com este grupo de psiquiatras militantes fundando as bases de uma prática psiquiátrica inédita: cuidados, pesquisa e formação agindo articuladas por um coletivo, operando clandestinamente quando da luta da Resistência contra a ocupação nazista. As situações emergentes deram as pistas: por exemplo, a partir do momento em que foi paralisada a circulação de mercadorias para os internados, ficando eles sem reposição de calçados, Bouvet (ainda diretor) se surpreende ao deparar-se com um interno delirante fabricando seus sapatos com materiais da oficina. Neste embalo, Bouvet que ele, frente a uma demanda absolutamente real e urgente, fabrique sapatos também para os demais, neste caso sendo remunerado, o que foi aceito e efetivado.

Quanto ao impacto destas experimentações no movimento pela Reforma Psiquiátrica e Desinstitucionalização no Brasil, Tosquelles é colocado como ator do que se considera uma etapa superada, como foi sinalizado a respeito do dispositivo Oficina (ou Atelier, em francês). Ora, Tosquelles tinha o entendimento de que o que havia até então era "ocupacionismo", a mesma percepção que se pode ter sobre o assunto com base na observação e em parte da literatura publicada no Brasil. Hoje este dispositivo se apresenta como projeto de reabilitação ou reinserção social, "através de ações que envolvem o trabalho, a criação de um produto, a geração de renda e a autonomia do sujeito" (COSTA \& FIGUEIREDO, 2004, p. 7). As propostas do movimento reformista tornaram-se lei e o processo de Desinstitucionalização ainda busca seu curso, correndo-se o risco de manicomialização dos serviços alternativos. Neste contexto, a pesquisa bibliográfica efetuada registra que a Psicoterapia Institucional (onde retirar "em geral é situado"em geral é situado Tosquelles costuma ser situado) é predominantemente citada como uma influência menor se comparada a outras experimentações, especialmente a italiana, via Basaglia e a Psiquiatria Democrática. 0 patrimônio gerado por Tosquelles e "a banda" costumam ser referidas como limitadas, pois que não ultrapassando os muros do asilo, encaminhando mudanças que ficariam restritas ao âmbito asilar considerando-as assim uma das "Psiquiatrias Reformadas":

A psicoterapia institucional e as comunidades terapêuticas, representando as reformas restritas ao âmbito asilar; a psiquiatria de setor e a psiquiatria preventiva, representando um nível de superação das reformas restritas ao âmbito asilar; por fim, a antipsiquiatria e as experiências surgidas a partir de Franco Basaglia, como instauradoras de rupturas com os movimentos anteriores, colocando em questão o 
Valéria Salek Ruiz, Vladimir Athayde, I rapoan Nogueira Filho, Paulo César Zambroni-de-Souza, Milton Athayde

François Tosquelles, sua história no campo da Reforma Psiquiátrica / Desinstitucionalização e suas pistas para uma abordagem clínica do trabalho centrada na atividade

próprio dispositivo médico-psiquiátrico e as instituições e dispositivos relacionados. (AMARANTE, 2003b, p.27)

Embora assim criticada no Brasil por não romper com o dispositivo asilar, é o próprio Tosquelles (GALLIO e CONSTANTINO, 1994) que, ao analisar o que deu certo em Saint-Alban, destaca a heterogeneidade e a permeabilidade do hospital como características determinantes do seu relativo sucesso. É importante registrar que Passos (2009), após pesquisa em que visitou as experiências da França (Psiquiatria de Setor) e Itália, faz considerações interessantes a respeito. Por exemplo, sobre a experiência francesa da Psiquiatria de Setor, ela nos diz que "muito pouco se conhece no Brasil sobre a maior reforma psiquiátrica já ocorrida na França desde Pinel". E acrescenta em nota de rodapé nunca ter conseguido "encontrar um único texto brasileiro que desse conta da história do setor de forma mais organizada [...]. Contraditoriamente, não faltam entre nós referências críticas generalizadas ao modelo" (p.40). Ao buscar razões para o descaso com outros "modelos" que não o italiano, ela diz que "uma delas é, seguramente, a rejeição ideológica de nossa luta antimanicomial, que costuma rejeitar em conjunto a psicoterapia institucional e a psiquiatria de setor" (p. 41). Quanto à Psicoterapia Institucional, ela seria combatida "por conter o ideal do "bom manicômio'" (id. ibid.). Enfim, como aceitar esse tipo de redução crítica à experimentação de psiquiatras deste calibre libertário, no campo cultural, político e profissional, como Tosquelles e outros?

O que Passos registra, Amarante (2007, p.108) confirma: “[...] já em relação à Psicoterapia Institucional, são raras as publicações no Brasil" e cita uma entrevista de Tosquelles e um artigo de autores brasileiros sobre ela. Mas não se trata apenas de ausência de publicações brasileiras a respeito, cabe registar também que a maior parte dos comentários sobre Tosquelles está em descompasso com sua riqueza. No livro Loucos pela vida (2003b), Amarante apresenta com seu grupo o resultado de uma rica e extensa pesquisa a respeito da trajetória da Reforma Psiquiátrica no Brasil, com uma análise cuidadosa da sua evolução conceitual. É nesse contexto de riqueza histórica e conceitual, que a "Psiquiatria Reformada"5 liderada por Tosquelles é localizada, reiterando a periodização apresentada por Birman e Costa em 1976 (1994). A Psicoterapia Institucional é apresentada exclusivamente com base no texto de Manuela Fleming (1976). Em livro recente, Amarante (2007, p. 43) assim se refere à experimentação de Tosquelles, situando-a no mesmo grupo da Comunidade Terapêutica: "A outra experiência de transformação do hospital psiquiátrico no período do pós-guerra ocorreu na França [...]". É neste contexto, assumido por Amarante como de escassas referências à Psiquiatria e Psicoterapia Institucional, que aqui se argumenta, buscando registrar que as ousadas e criativas iniciativas 
de Tosquelles remetem ao período da Guerra Civil Espanhola e o maior impacto das experimentações de Saint Alban se desenvolveram já durante a 2a Guerra Mundial.

Revela-se necessário, mas insuficiente fazer a crítica da "trajetória higienista" (GUERRA, 2004) no Brasil. É o caso das colônias agrícolas - seja com suas atividades rurais, ligadas ao setor primário da economia, seja com atividades tipicamente manufatureiras, para os homens. Já que ela ocorreu, caberia aproveitar para indagar: que efeitos, ganhos e perdas elas trouxeram para os ali internados? A respeito disto praticamente nada foi encontrado na literatura a que se teve acesso. Quanto à realidade vivida por Tosquelles, temos um patrimônio importante a respeito, por ele próprio, parcialmente (1967] 2009).

Tem-se aí algumas pistas do patrimônio a que se chegou neste campo. Pode ser referida a questão da remuneração - não se usa o conceito de "renda", como hoje na Reforma - tomada como questãonão se usa o conceito de "renda", como hoje na Reforma - tomada como questão, o que envolveu um grande e rico debate entre os maiores psiquiatras sociais na França, como o fundador da Psicopatologia do Trabalho, Le Guillant, com posições divergentes entre eles (BILLIARD, 2001; ZAMBRONI-DE-SOUZA e ATHAYDE, 2006). Pode-se também assinalar a questão do engajamento/desengajamento no trabalho, neste caso tem-se rigorosas considerações, seja de Simon, Sivadon (que apresenta um rigoroso protocolo a ser verificado, atentamente, caso a caso, para a prescrição e acompanhamento do curso das atividades), Koechli (com uma proposta de três etapas práticas) etc. Além de ricas pistas para a atividade de observação por parte da equipe.

\section{Tosquelles visto pelo movimento institucionalista}

Não apenas no campo da Reforma Psiquiátrica, também no campo do Movimento Institucionalista Tosquelles é registrado como um precursor: "o movimento institucionalista vai nascer no terreno da psiquiatria durante a guerra de 1940-1945" (HESS, 1983, p. 163). É frequente referir-se ao movimento de Análise Institucional como tendo passado por três etapas, sendo a Psicoterapia Institucional a primeira, no campo da psicoterapia de asilo (p. 169), a segunda se operando no terreno da pedagogia - a Pedagogia Institucional, em suas diferentes orientações, seja a psicanalítica (F. Oury, A. Vasquez etc.) ou autogestionária (M. Lobrot, R. Lourau etc.). As duas seriam as "raízes", as fontes da Al.

Hess (op. cit.) identifica a presença de Tosquelles, seja na primeira fase (PI), seja posteriormente, quando Lapassade no campo da formação, no início dos anos 1960 (p. 169): “[...] reproduzia num 

centrada na atividade

outro campo a descoberta da psicoterapia institucional [...]". Embora haja reconhecimento do quanto Jean Oury aprendeu com a experimentação dirigida por Tosquelles, de fato o que mais teve destaque no Brasil foi a experiência clínica de La Borde, que Oury vai buscar desenvolver a seu modo, com o tempero da participação de Felix Guattari, também ele então sob forte influência lacaniana.

Ainda segundo Hess, a PI influenciou diversas correntes do movimento institucionalista, como a Análise Institucional (AI), a Pedagogia Institucional (especialmente com Freinet), a Psicossociologia, e o movimento pelas reformas psiquiátricas que se sucederam, na França (Psiquiatria de Setor) e também em outros países.

Já Moura (2003, p. 66-67) assinala a participação destacada de Guattari neste processo, cujo entendimento pode nos levar a uma outra leitura. O autor registra que foi Guattari quem criou o termo Análise Institucional, ao buscar uma outra via analítica que permitisse maior transversalidade aos diversos campos empíricos. Tratar-se-ia de uma preocupação absolutamente relevante na prática de $\mathrm{PI}$, algo que a corrente de Lourau e outros não teria contemplado. Para Guattari (1985), sua concepção seria claramente diferente da corrente liderada por Lourau:

Infelizmente esta expressão 'análise institucional' foi retomada por pessoas que certamente não careciam de talento (tais como Lourau, Lobrot, Lapassade etc.), mas em uma perspectiva psicossociológica por demais reducionista para meu gosto. (apud MOURA, 2003, p. 67)

É assim que Moura (op. cit., p. 68) nos recorda a incisiva posição de Tosquelles (1985, p.155): "sem análise institucional, a psicoterapia institucional às vezes empreendida, é sempre automaticamente e sistematicamente destruída, sem que os próprios terapeutas sejam advertidos dos perigos que surgem no círculo de suas próprias ações". Reitera Moura (op. cit., p.68): "sem uma análise institucional, portanto, a psicoterapia institucional perde o seu poder de tratamento, (...) uma não vai sem a outra".

\section{As abordagens clínicas do trabalho e a ênfase na atividade}

A Psicologia do Trabalho \& Organizacional (PT\&O) em regra considera o patrimônio exclusivamente experiências envolvendo o trabalho no campo da normalidade. Não é incorreto dizer que, quase sempre sem sabê-lo, também daqueles que se situam na normopatia. Fica como ponto cego o que se processa no negativo, como o que, mal ou bem, se desenvolve no campo de experiência dos humanos tidos como sem 
razão. Contrariando essa lógica, instituiu-se na França um outro campo disciplinar, da Psicopatologia do Trabalho (PPT), criado pelos psiquiatras Louis Le Guillant (ATHAYDE, 1996; ZAMBRONI-DESOUZA, ATHAYDE, ARAÚJO e SOUZA, 2009; ZAMBRONI-DE-SOUZA e ATHAYDE, 2006) e Paul Sivadon (BILLIARD, 2001).

Entretanto, ainda se pode registrar aí presente elementos que ficam fora do plano da compreensão, pois a PPT costuma ter visibilidade na comunidade científica e dos profissionais de intervenção no campo da Saúde Mental apenas na medida em que se investigam os riscos de adoecimento mental daqueles que, no campo da normalidade, ainda trabalham. As experimentações daqueles psiquiatras - de Simon a Tosquelles - que, de modo tão fértil e consistente contemplam a experiência-trabalho em situações-limite, costumam ser ignorados ou, no mínimo, pouco valorizados.

É surpreendente que neste campo da PPT, onde o psiquiatra Christophe Dejours se situava, em seu primeiro livro publicado na França, em 1980, Travail, usure mentale: essai de psychopathologie du travail (no Brasil, em 1987, com o título "A loucura do trabalho: estudo de psicopatologia do trabalho"), Tosquelles está absolutamente ausente, mesmo na Introdução, onde o autor apresenta a história das relações entre trabalho e saúde mental.

Mas é o próprio Dejours que, na nova edição de seu primeiro livro (1993) reconhece que seria necessária uma análise mais ampla, pois as situações de efetiva psicopatologia engendrada pelo trabalho não são a regra, apesar da frequência de modalidades e situações de trabalho patogênicas. Ele propõe então a criação da Psicodinâmica do Trabalho (PDT), no interior da qual se situaria a PPT. Antes disso, no Colóquio sobre Psicopatologia do Trabalho, por ele organizado junto com Claude Veil e Alain Wisner, no período 1984-85, ele e Dopler (DOPLER; DEJOURS, 1985) apresentaram a PPT dividida em seis campos.

Primeiro, o da "desadaptação do homem ao trabalho", desenvolvida sobretudo nos anos 1960 por Sivadon, Amiel, posteriormente por Fernandez-Zoïla. É no segundo campo, concernindo as modalidades de readaptação psíquica dos trabalhadores, que os autores destacam Tosquelles, junto com Verbizier. O terceiro, contemplando as doenças mentais constatadas e ao trabalho como instrumento de reorganização mental, teria sido inaugurado na França por Sivadon (transformando o hospital Ville-Évrard que dirigia, em um Centro de Tratamento e Readadaptação Social - CTRS), após a Segunda Guerra (1947), introduzindo naquele país a Ergoterapia nos hospitais psiquiátricos, criando as oficinas protegidas. Quarto campo, o dos estudos sobre Higiene Mental do Trabalho, envolveu Veil e a Liga de Higiene Mental, nos anos 1960. O quinto campo é o das doenças mentais ocasionadas pelo trabalho, instituído nos anos 1950-60 por Le Guillant, Begoin e Pariente. Sexto campo, encaminhado por 
Dejours e sua corrente Association pour l'ouverture du champ d'investigation psychopathologique - AOCIP (ATHAYDE, 1996), contempla a psicopatologia do sofrimento no trabalho, investigando os efeitos mentais do trabalho, mesmo quando não se configuram doenças mentais constatadas, indagando-se como fazem os trabalhadores para se adaptar e suportar as exigências psíquicas do trabalho.

A esta lista, os autores apontam para um outro campo, até então pouco explorado na França, o da análise da relação psíquica com o trabalho em termos de estresse, muito desenvolvido nos EUA, Grã Bretanha, Canadá e nos países escandinavos.

É curioso, enfim, como foi assinalado, o quanto Dejours limita a importância de grandes psiquiatras da geração anterior, não só Tosquelles, até mesmo como sempre o fez com o rico patrimônio gerado por Le Guillant em sua trajetória. Dejours reitera os equívocos de Le Guillant e o quanto ele teria colaborado para a crise da PPT, nos anos 1960, campo que só teria se revigorado com a emergência do grupo liderado por Dejours (corrente AOCIP), no final dos anos 1970.

Para confirmar a regra, encontram-se exceções no campo da Psicopatologia do Trabalho, encontra-se como o permanente cuidado de Bernard Doray (1996) reivindicando a relevância de Le Guillant, ou a tese-livro de Isabelle Billiard (2001), onde os diversos atores, inclusive Tosquelles aparecem ao lado de Le Guillant, com rigoroso destaque. No campo da Psicologia do Trabalho, podem ser encontradas a sinalização de Yves Clot em alguns textos mais recentes, como em (2006a, 2009, 2010), para a importância de Tosquelles, assim como já o fizera com Le Guillant. Clot aí destaca as contribuições de Tosquelles como balizadoras da sua proposta de uma Psicologia da Ação ao lado de uma Clínica da Atividade. Ora, mas como não fazê-lo, ainda que tardiamente, dado que Clot propõe no interior das Clínicas do Trabalho, uma abordagem que designa por "Clínica da Atividade"? Tosquelles há décadas atrás já dava nobreza à atividade humana e às atividades de trabalho, em sua relação com a saúde mental. Clot reconhece que a proposta da Psicoterapia Institucional privilegiava a atividade não apenas como um objeto de estudo, mas como ferramenta de intervenção. Lecarpentier comentava a respeito:

\footnotetext{
“Tosquelles dizia: O homem não vive em um meio ou meio ambiente ao qual ele deve se adaptar ou mesmo morrer, o homem habita o mundo que ele constrói com os outros homens'" (apud MOURA, 2003, p. 102).
}

E em seu texto de 1984 Tosquelles chamava atenção para a denominação criada por Daumézon: "Clínica de Atividades". Como 

centrada na atividade

assinala Billiard (2001, p. 104), Daumézon endereça a seus colegas a seguinte recomendação: "convém anexar à velha pesquisa clínica (...) e sem dúvida substituí-la por uma clínica de atividades".

Já a partir da proposta da Ergoterapia, com Tosquelles os internados desenvolvem seus engajamentos em diferentes atividades de trabalho, não apenas para ocupar o tempo dito ocioso ou para reduzir seus sintomas. Um dos principais objetivos do trabalho seria o de colaborar para que o protagonista se deslocasse do lugar passivo de paciente, assumindo-se como ativo usuário, cuidando do próprio hospital como estabelecimento de cuidados, neste mesmo processo em que ativamente cuida de si e dos outros.

Tosquelles defende com exuberância que o hospital psiquiátrico deveria ser, resgatando a expressão criada por um seu paciente, uma "escola de liberdade" (GALLIO e CONSTANTINO, 1994) um local onde zonas de liberdade deveriam ser criadas, insistindo em colocar o termo no plural.

No tipo de encaminhamento de Ergoterapia conduzido por Tosquelles, o trabalho de 'cuidar da instituição' é realizado em conjunto com os que são tradicionalmente os profissionais de cuidados. Ou seja, tratase de uma atividade que então se desdobra - uma atividade sobre a atividade, uma atividade de diálogo sobre a atividade, onde o interlocutor é afetado por sua atividade repetida e retomada por outro (CLOT, 2006b). Esta situação de trabalho possibilita um reposicionamento do usuário, que tradicionalmente ocupou na Psiquiatria um lugar mais passivo ("paciente"), de objeto de intervenções de outrem. Neste reposicionamento, o foco de atenção terapêutica também já não se concentra apenas nas histórias pessoais dos internados, como também, e principalmente, nas vicissitudes das situações concretas de vida e trabalho.

Para Tosquelles (1967), na medida em que o doente busca cuidar de si mesmo, neste mesmo movimento modifica-se o próprio processo de trabalho terapêutico, pois o usuário do Serviço passa a atuar como coprodutor do serviço de atenção psicossocial (ZARIFIAN, 2001).

\section{Pesquisa bibliográfica}

Enfim, apresenta-se a seguir os textos de Tosquelles fruto do levantamento bibliográfico efetuado:

Le coin du médecin. Trait d'union. n. 36, 1951.

Symposium sur la psychothérapie collective. Évolution psychiatrique, n. 4, p. 553-54, 1952.

Higiène mentale des éducateurs. Paris: Herman, 1962.

La réeducation des débiles mentaux : Introduction à I' aide maternelle et a I'education thérapeutique. Toulouse: Privat, [1964]1975. 
Pédagogie et psychothérapie institutionnelles. Paris : S. de P.I., 1966.

La pratique du maternage thérapeutique chez les débiles mentales profonds. Paris : J.-L. Aupetit, 1966.

Le travail thérapeutique à I'hôpital psychiatrique. Paris: Eds. du Scarabée, 1967.

Structure et réeducation thérapeutique. Paris : Ed. Universitaire, 1967.

Structure et réeducation thérapeutique. Aspects pratiques. Paris : Editions Universitaires, [1967]1970.

Positions sur I'analyse institutionelle. Conexions, n. 6, 1973.

Coletivo. Histoire de la psychiatrie de secteur ou le secteur impossible ? Recherches, n. 17, 1975.

Pédagogie et psychotérapie institucionnelle. Mantes1975-laVille: Hiatus, 1984.

Entrevista. In: J. Oury, F. Guattari, F. Tosquelles. Pratique de I' institutionnel et politique. Paris: Matrice, 1985a, p. 87-128.

Revenons sur la notion de d'institution. In: J. Oury, F. Guattari, F. Tosquelles. Pratique de I'institutionnel et politique. Paris: Matrice, 1985b, p. 129-163.

Le vécu de la fin du monde dans la folie. Édition de I' Arefppi, 1986.

Le travail des jours qui passent. In: M. Minard (org.) Une psychiatrie en travail. Toulouse: Érès, 1990.

L'enseignement de la folie. Paris: Dunod, 1992.

La réeducation des débiles mentaux. Toulouse: Privat, 1993.

Actualité de la psychotérapie institutionnelle. Parias: Matrice, 1994

Collective. De la personne au groupe. À propos des equipes des soins. Toulouse: Érès, [1995] /2003a.

Fonction poétique et psychotérapie. Toulouse : Érès, 2003b.

Cours aus éducateurs. Nimes: Champs social éditions, 2003.

Tosquelles, F., J. Oury e F. Guattari (org.). Pratique de I' institutionnel et politique. Vigneux: Matrice, 1985.

Tosquelles, F. e Ellul, J. La genèse aujourd' hui. Paris: Éditions de Arefppi, 1987.

\section{Conclusões}

Desde 1700, na Itália, com Ramazzini e seu livro-referência A doença dos trabalhadores, sabe-se da importância de perguntar aos doentes, quando da anamnese médica: que tipo de trabalho você faz? Ele então desloca o olhar sobre o paciente do plano do consumo para o da produção, assim como o retira do olhar de uma especialidade específica da Medicina (FERREIRA, 2001). Séculos depois, a questão 
da atividade humana e em especial a atividade de trabalho continua, embora frequentemente negligenciada, como problema por melhor colocar e encaminhar, nos planos teórico, metodológico e técnico.

Buscou-se no artigo ressaltar que as experiências de Tosquelles podem oferecer importantes subsídios para desenvolver teorias e práticas e fundamentar as já existentes, especialmente no contexto dos novos dispositivos de atenção psicossocial (AMARANTE, 2007) e nas chamadas clínicas do trabalho que valorizam o ponto de vista da atividade, como a Ergonomia (HUBAULT, 2004), a Clínica da Atividade (CLOT, 2006b), etc.

Procurou-se no artigo seguir algumas pistas abertas por Tosquelles, dentre elas tomar a atividade como ponto de partida para as análises e intervenções no trabalho em saúde mental. Nesse sentido, pode-se também afirmar a gestão da saúde e da vida como algo que diz respeito a todos, inclusive àqueles que vivem a experiência, não devendo ficar restritos aos especialistas no assunto, mesmo porque, esses terão passado pela "deformação profissional" a que se referiu o autor.

Esta démarche ajuda a deslocar de uma condição de passividade sugerida e esperada, de mero objeto de intervenção de outrem e de impotência frente os agravos em saúde e à inexorável existência, para um posicionamento ativo. Esta perspectiva segue na direção das proposições defendidas por Georges Canguilhem (2001), explorada na Ergologia por Yves Schwartz (1992), quando pensam a saúde em sua relação com a normatividade, assim como Dejours (1986, 1991, 1993) e por Clot, no desenvolvimento do "poder de agir sobre o mundo e sobre si" (CLOT, 2006a, 2010).

As transformações surgidas no contexto da Reforma Psiquiátrica brasileira envolvem aspectos que remetem tanto ao âmbito da assistência direta ao usuário, como ao da forma de organização desta assistência. As mudanças desencadeadas instauram uma desconstrução em cadeia: a do papel dos especialistas (seja enquanto operadores da organização administrativa ou da prática clínica), a do lugar de passividade atribuído aos que seriam o objeto da intervenção (sejam os "pacientes"/"doentes mentais" ou trabalhadores/"recursos humanos"), e a do próprio objetivo da intervenção. Este processo, quando posto em funcionamento, não é delimitável ao âmbito de nenhuma outra prática tomada de forma isolada, produzindo efeitos em cadeia, transformando não só o objeto e o operador da intervenção, mas o seu próprio objetivo ${ }^{7}$.

\section{Referências}

AMARANTE, P. Psiquiatria social e reforma psiquiátrica. Rio de Janeiro: Ed. Fiocruz, 1994. 
(Org.). O homem e a serpente: outras histórias para a Toucura e a psiquiatria. 2. reimp. Rio de Janeiro: EdFiocruz, 2003a.

Loucos pela vida: a trajetória da reforma psiquiátrica no Brasil. 2. ed., 3. reimp. Rio de J aneiro: EdFiocruz, 2003b.

Saúde Mental e atenção psicossocial. Rio de Janeiro: Ë̄Fiocruz, 2007.

ATHAYDE, M. Coletivos de trabalho e modernização: questões para a Engenharia de Produção. 1996. 260p. Tese (Doutorado em Engenharia de Produção/Ergonomia) - Coppe, Universidade Federal do Rio de Janeiro, Rio de Janeiro.

BARROS, R. B. B. Grupo: a afirmação de um simulacro. Porto Alegre: Sulina/Ed. UFRGS, 2007.

BILLIARD, I. Santé mentale et travail: L'émergence de la psychopathologie du travail. Paris: La Dispute, 2001.

BIRMAN, J.; COSTA, J. F. Organização de instituições para uma psiquiatria comunitária. In: Amarante, P. (org.). Psiquiatria social e reforma psiquiátrica. Rio de Janeiro: Ed. Fiocruz, 1994.

BRASIL. Saúde mental e economia solidária: inclusão social pelo trabalho. Ministério da Saúde. Secretaria de Atenção à Saúde. Departamento de Ações Programáticas Estratégicas. Brasília: Ed. Ministério da Saúde, 2005.

CANGUILHEM, G. Meio e normas do homem no trabalho. Proposições, Campinas, v. 12, n. 2-3, p. 109-121, [1947], 2001.

CASTEL, R. Rumo às novas fronteiras da Medicina Mental. In: Figueira, S. A. (Org.). Psicanálise e ciências sociais. Rio de Janeiro: Francisco Alves, 1980, p. 246-280.

CLOT, Y. Après Le Guillant: quelle clinique du travail? In: Le Guillant, L. Le drame humaine du travail: Essais de psychopatologie du travail. Paris: Érès, 2006a, p. 7-36.

$\overline{2} \overline{0} \overline{6} \bar{b}$.

.A função psicológica do trabalho. Petrópolis: Vozes,

Postface: L'apport de François Tosquelles à la clinique du travail. In: TOSQUELLES, $F$. Le travail thérapeutique en psychiatrie. Paris: Érès, [1967] 2009, p. 143-162.

$\overline{2} 0 \overline{10}$.

Trabalho e poder de agir. Belo Horizonte: Fabrefactum,

DAUMEZON, G.; KOECHLIN, P. La psychothérapie institutionnelle française. Anais portugueses de psiquiatria, Lisboa, vol. 4, 1952.

DEJ OURS, C. Travail - usure mentale: essai de psychopatologie du travail. Paris: Bayard, 1980.

.Por um novo conceito de saúde. Revista Brasileira de

Saúde Ocupacional, São Paulo, v. 14, n. 54, p. 7-11, 1986.

. Normalidade, trabalho e cidadania. Cadernos CRP-06, São

Paulo, v. 6, n. 1, p. 13-17, 1991. 
Travail, usure mentale: Essai de psychopathologie du travail. Nouvelle édition augmentée - de la psychopathologie à la psychodynamique du travail. Paris: Bayard, 1993.

DELION, P. Préface. In: Tosquelles, F. Le travail thérapeutique em psychiatrie. Paris: Érès, [1967] 2009, p. 7-15.

DESVIAT, M. A Reforma Psiquiátrica. Rio de Janeiro: Fiocruz, 1999.

DOPLER, F.; DEJOURS, C. Psychopatologie du Travail: propositions initiales. In: DEJ OURS, C.; VEIL, C.; WISNER, A. (Org.) Psychopatologie du Travail. Paris:Entreprise Moderne d'Édition, 1985.

DORAY, B. Un regard sur l'oeuvre de Louis Le Guillant dans le domaine de la Psychopathologie du Travail. In: CLOT, Y. (Org.), Les histoires de la psychologie du travail: Approche Pluridisciplinaire.Toulouse: Octarès, 1996, p. 125-138.

FERREIRA, L. L. 'Quam artem exerceas?'. Travailler, Paris, v.1, n.5, p. 219-224, 2001.

FLEMING, M. I deologias e práticas psiquiátricas. Porto: Afrontamento, 1976.

GALENDE, E. Psicoanálisis y salud mental - Para uma crítica de la razón psiquiátrica. Buenos Aires: Paidos, 1990.

GALLIO, G.; CONSTANTINO, M. François Tosquelles: a escola da liberdade. In: LANCETTI, A. (Org.) Saúdeloucura: grupos e coletivos. São Paulo: Hucitec, 1994, p. 85-128.

GUATTARI, F. Entrevista. In: OURY, J.; GUATTARI, F.; TOSQUELLES, F. (Org.), Pratique de l' institutionnel et politique. Vigneux: Matrice, 1985, p. 45-83.

GUERRA, A. M. C. - Oficinas em saúde mental: percurso de uma história, fundamentos de uma prática. In: Costa, C. e Figueiredo, A. C. (Oorg.) - Oficinas terapêuticas em saúde mental: sujeito, produção e cidadania. Rio de Janeiro: Contra Capa, 2004, p. 2358.

HESS, R. Sociologia da intervenção. Porto: Rés, 1983.

HUBAULT, F. Do que a Ergonomia pode fazer a análise? In: DANIELLOU, F. (Org.), A Ergonomia em busca de seus princípios: debates epistemológicos. São Paulo:Edgard Blücher, 2004.

MANNONI, M. O psiquiatra, seu "Iouco" e a Psicanálise. Rio de J aneiro:Zahar, 1070.

MENEZES, M. T. Economia solidária: elementos para uma crítica marxista. Rio de Janeiro: Gramma, 2007.

MOURA, A. H. A psicoterapia institucional e o clube dos saberes. São Paulo: Hucitec, 2003.

NICÁCIO, M. F. (Org.). Desinstitucionalização. São Paulo: Hucitec, 1990. 
François Tosquelles, sua história no campo da Reforma Psiquiátrica / Desinstitucionalização e suas pistas para uma abordagem clínica do trabalho centrada na atividade

Utopia da realidade: contribuições da desinstitucionalização para a invenção de serviços de saúde mental. 2003. 224f. Tese (Doutorado em Saúde Coletiva) - Universidade Estadual de Campinas, Campinas.

NOGUEIRA FILHO, I. Inventividade, atividade de trabalho e transtornos mentais graves: um ensaio no campo da cognição. 2008. 101f. Dissertação (Mestrado em Psicologia Social). Programa de Pós-graduação em Psicologia Social, Universidade do Estado do Rio de Janeiro, Rio de Janeiro, 2008.

OURY, J. O coletivo. São Paulo: Hucitec, 2009.

PASSOS, I. C. Reforma psiquiátrica: as experiências francesa e italiana. Rio de Janeiro: Ed. Fiocruz, 2009.

RODRIGUES, H. As subjetividades em revolta: institucionalismo francês e novas análises. 1993. 984f. Dissertação (Mestrado em Saúde Coletiva) - Instituto de Medicina Social, Universidade do Estado do Rio de Janeiro, Rio de Janeiro.

Um anarquista catalão: aventuras do freudo-marxismo na

França. Cadernos de Psicologia, Rio de Janeiro, v. 8, p. 151-170, 1998.

ROTELLI, F. Empresa social. In: AMARANTE, P. (Org.). Ensaios: subjetividade, saúde mental e sociedade. Rio de Janeiro: EdFiocruz, 2000.

ROUDINESCO, E. História da psicanálise na França. Rio de Janeiro: Zahar, 1988.

RUFFEIL, N. Ergo(trans)formação: curtos circuitos entre o trabalhar e os processos de subjetivação. 2009. 232 f. Tese (Doutorado em Psicologia Social). Programa de Pós-graduação em Psicologia Social, Universidade do Estado do Rio de Janeiro, Rio de Janeiro, 2009.

SARACENO, B. Libertando identidades: da reabilitação psicossocial à cidadania possível. 2. ed. Rio de Janeiro: Te Corá/Instituto Franco Basaglia, 2001.

SCHIOCHET, V. Economia Solidária e Saúde Mental. In: BRASIL, Saúde mental e economia solidária: inclusão social pelo trabalho. Ministério da Saúde. Secretaria de Atenção à Saúde. Departamento de Ações Programáticas Estratégicas. Brasília: Ed. Ministério da Saúde, 2005.

SCHWARTZ, Y. Travail et philosophie: convocations mutuelles. Toulouse: Octarès, 1992.

SIMON, H. Terapéutica activa en el sanatorio psiquiátrico, 1927. Tratamiento ocupacional de los enfermos mentales. Barcelona: Salvat, 1937.

TOSQUELLES, F. Éducation et psychotérapie institutionelle. Mantes-la-Ville: Hiatus, 1984. 
François Tosquelles, sua história no campo da Reforma Psiquiátrica / Desinstitucionalização e suas pistas para uma abordagem clínica do trabalho centrada na atividade

Revenons sur la notion d'institucion In: OURY, J.; GŨATTARI, F.; TOSQUELLES, F. (Org.), Pratique de I' institutionnel et politique. Vigneux: Matrice, 1985, p. 129-163. ['] $\overline{19} \overline{6} \overline{7}] 2009$.

Le travail thérapeutique em psychiatrie. Paris: Érès,

VERTZMAN, J.; CAVALCANTI, M. T.; SERPA Jr, O. Psicoterapia institucional: uma revisão. In: BEZERRA JR, B. \& P. AMARANTE, P. (Org.). Psiquiatria sem hospício: contribuições ao estudo da reforma psiquiátrica. Rio de Janeiro: Relume Dumará, 1992, p. 1730.

ZAMBRONI-DE-SOUZA, P.C. O trabalho como possível: o caso das pessoas com "transtornos mentais graves". 2006. 232f. Tese (Doutorado em Psicologia Social). Programa de Pós-graduação em Psicologia Social, Universidade do Estado do Rio de Janeiro, Rio de Janeiro, 2006.

ZAMBRONI-DE-SOUZA, P.C.; ATHAYDE, M. A contribuição da abordagem clínica de Louis Le Guillant para o desenvolvimento da Psicologia do Trabalho. Estudos e Pesquisas em Psicologia, Rio de Janeiro, v. 6, n. 1, p. 6-19, 2006.

ZAMBRONI-DE-SOUZA, P.C.; ATHAYDE, M.; ARAÚJO, A. e SOUZA, A. O pioneirismo de Louis Le Guillant na reforma psiquiátrica e psicoterapia institucional na França: a importância do trabalho dos pacientes para a abertura dos hospícios. Estudos e Pesquisas em Psicologia, Rio de Janeiro, v. 9, n. 3, p. 612-631, 2009.

ZARIFIAN, P. Mutação dos sistemas produtivos e competências profissionais: a produção industrial de serviço. In SALERNO, M. (Org.). Relação de serviço: produção e avaliação. São Paulo: Editora Senac, 2001, p. 67-94.

\section{Endereço para correspondência \\ Valéria Salek Ruiz}

Av. Almirante Barroso, 81, $23^{\circ}$ andar - Centro, Rio de Janeiro. CEP: 20031-004

Endereço eletrônico: val.ruiz@hotmail.com

Vladimir Athayde

Praça 1 de Maio s/n, Bangu, CEP 21830-006, Rio de Janeiro-RJ, Brasil.

Endereço eletrônico: vladimirathayde@gmail.com

I rapoan Nogueira Filho

Avenida Prefeito Alberto da Silva Lavinas, 1847, sala 11, CEP 25802-100, Três Rios, RJ, Brasil

Endereço eletrônico: infilho@gmail.com

Paulo César Zambroni-de-Souza

Cidade Universitária, Conjunto Castelo Branco, J oão Pessoa-PB, Brasil, CEP 58.059900.

Endereço eletrônico: paulozamsouza@yahoo.com.br

Milton Athayde

Rua São Francisco Xavier, 524, Maracanã, CEP 20550-013, Rio de Janeiro-RJ,

Brasil.

Endereço eletrônico: athayde.milton@gmail.com 
Valéria Salek Ruiz, Vladimir Athayde, Irapoan Nogueira Filho, Paulo César Zambroni-de-Souza, Milton Athayde

François Tosquelles, sua história no campo da Reforma Psiquiátrica / Desinstitucionalização e suas pistas para uma abordagem clínica do trabalho centrada na atividade

Recebido em: 16/09/2011

Reformulado em: 01/02/2012

Aceito para publicação em: 27/02/2012

Acompanhamento do processo editorial: Deise Mancebo

\section{Notas}

* Psicóloga da Petrobras, Rio de Janeiro, Brasil. Mestre e Doutora pela Universidade do Estado do Rio de Janeiro.

** Psicólogo do Hospital da Mulher Masriska Ribeiro, Rio de Janeiro-RJ, Brasil. Especialista em Saúde Mental e Atenção Psicossocial, Especialista em Saúde do Trabalhador e Ecologia Humana e Mestre em Saúde Pública pela Escola Nacional de Saúde Pública/FIOCRUZ.

*** Professor da Universidade Federal Rural do Rio de Janeiro. Mestre e Doutor em Psicologia Social pela Universidade do Estado do Rio de J aneiro.

**** Professor do Programa de Pós-graduação em Psicologia Social da Universidade Federal da Paraíba. Doutor em Psicologia Social pela Universidade do Estado do Rio de Janeiro.

***** Professor do Programa de Pós-graduação em Psicologia Social da Universidade do Estado do Rio de Janeiro. Doutor em Engenharia de Produção/Ergonomia (Coppe/UFRJ), Pós-Doutorado em Ergologia (Aix-Marseille Université) e em Psicologia do Trabalho (Universidade do Porto, Portugal).

${ }^{1}$ Para ilustrar esta idéia da distância lembramos o relato de Tosquelles em 1994 (GALLIO; CONSTANTINO, 1997) que ao receber o convite de Balvet para trabalhar no Hospital olhou no mapa e não localizou Saint-Alban. Mas, disse ele, "gosto de ir em lugares que não se ouve falar" (p.91).

${ }^{2}$ Outro psiquiatra e psicanalista que se tornou uma das referências nesta linhagem, J ean Oury (2009) fundador em 1953 da Clínica (privada) de La Borde, lembra que Tosquelles explorava e privilegiava esta noção de passagem já em um pequeno artigo de 1960 sobre a "semiologia dos grupos".

${ }^{3}$ A esse respeito, ao lado dos textos de Paul Singer e dos textos que buscam avaliar a Economia Solidária, temos poucos textos críticos. Pode-se ler o livro de Menezes (2007), em uma crítica que se pretende marxiana, corrente lukacsiana. No que tange ao foco do artigo, recentemente ela tornou-se no Brasil política pública, diríamos compensatória, frente à miséria e ao desemprego, com a pretensão de que ela se configura em uma lógica oposta ao modo de produção capitalista.

${ }^{4}$ A esse respeito uma referência atual é a tese-livro de Moura (2003).

5 Como referem os autores, a expressão foi "proposta por Franco Rotelli (1990, p.17-59) para mapear os movimentos reformistas da psiquiatria na contemporaneidade" (Amarante, 2003b, p. 27).

${ }^{6}$ Tosquelles (op. cit.) insiste em colocar o termo no plural. Ele ilustra também com situações, como as reuniões das cooperativas de trabalho: quando chegava alguém com delírios e alucinações eram feitas intervenções no sentido de manter o foco da pauta em termos de processo de trabalho e comercialização, como o corte de tecido, preço do café, etc.

7 Este processo de transformações, que envolvem as mudanças de concepções e paradigmas tem sido discutido no movimento da Reforma Psiquiátrica, como no livro organizado por Nicácio (1990). 